\title{
Analysis of tidal expiratory flow pattern in the assessment of histamine-induced bronchoconstriction
}

\author{
M J Morris, R G Madgwick, D J Lane
}

\begin{abstract}
Background - There are times in clinical practice when it would be useful to be able to assess the severity of airways obstruction from tidal breathing. Three indices of airways obstruction derived from analysis of resting tidal expiratory flow have previously been described: (1) Tme/ $\mathrm{TE}=$ time to reach maximum expiratory flow/expiratory time; (2) $\mathrm{Krs}=$ decay constant of exponential fitted to tidal expiratory flow versus time curve; and (3) $\mathbf{E V}=$ extrapolated volume - that is, area under the curve when the fitted exponential is extrapolated to zero flow. In this paper a further index - dt/TE, time from the beginning of expiration till the rapid decay of flow begins/expiratory time - is evaluated. The aim of this study was to assess the ability of these indices to detect mild airways obstruction.
\end{abstract}

Methods - A histamine bronchial provocation test was performed in 20 adult patients with a diagnosis of asthma or symptoms of cough and/or shortness of breath. Baseline forced expiratory volume in one second $\left(F E V_{1}\right)$, functional residual capacity (FRC), and specific inspiratory conductance (sGaw) were measured and the measurements repeated after the final inhalation of histamine. Expiratory flow patterns during quiet breathing over five consecutive representative breaths were analysed before and after histamine. The test was concluded in 12 subjects when FEV $_{1}$ had decreased by $20 \%$ of the post saline value, and in the remaining eight after inhalation of 16 or $32 \mathrm{mg} / \mathrm{ml}$ histamine.

Results - FEV 1 , sGaw, FRC, Krs, EV, and $\mathrm{dt}_{\mathbf{T}} / \mathrm{TE}$ were all different after histamine (paired $t$ test). For Tme/TE no difference was shown. Change in EV detected change in end tidal volume but underestimated it compared with the change measured by body plethysmography. Percentage fall in Krs after histamine correlated with percentage fall in $\mathrm{FEV}_{1}(r=0.527$, Pearson correlation coefficient). This was of a similar order to the correlation between the percentage fall in $\mathrm{sGaw}$ and in $\mathrm{FEV}_{1}(r=$ 0.543).

Conclusions - Analysis of expiratory tidal flow-time patterns predicted a decrease in $\mathrm{FEV}_{1}$ following histamine challenge as did measurement of sGaw. This analysis of tidal breathing would be useful in circumstances where forced expiratory manoeuvres are unreliable or inapplicable. (Thorax 1995;50:346-352)

Keywords: tidal expiratory flow, histamine-induced bronchoconstriction.

Expiratory tidal flow has a different pattern in patients with significant airways obstruction $\overrightarrow{ }$ than in normal subjects. ${ }^{1-7}$ Buohuys ${ }^{4}$ stated in 1957 that "in most cases the difference between normal and abnormal records can be seen at a $\vec{\bullet}$ glance: the abnormal records show a constant on pattern in all cycles, the maximum expiratory flow rate is reached early in expiration and the record is smooth without the normal small variations in flow rate". In his study, although he found the time to reach maximal tidal expiratory flow considerably shortened in patients with significant airways obstruction, he felt the degree of overlapping of normal with abnormal subjects for this finding was such that it could not be used to distinguish normal from abnormal records.

The most commonly employed tests of airways obstruction are those in which maximally forced flow rates are measured. Such tests are not applicable in uncooperative or unconscious adult patients, or in infants or young children. In such circumstances, and in large epidemiological studies, a portable test of airways obstruction requiring only a short run of tidal breathing would be useful. With the recent emphasis on the benefits of non-invasive technology and the advent of computerisation there $\omega$ has been a resurgence of interest in the analysis of tidal flow patterns as a tool in the assessment 0 of airways obstruction. This has resulted in a $\mathbb{D}$ growing core of published work, mainly by paediatricians, to validate these measurements. ${ }^{8-14}$

We have previously described three indices of airways obstruction derived from analysis of resting tidal expiratory flow ${ }^{67}$ (fig 1 ) and have postulated the following interpretations of these indices:

(1) $\mathrm{Tme} / \mathrm{TE}=$ time to reach maximum ex- 흥 piratory flow/expiratory time (this index was? originally described as $\mathrm{dt} / \mathrm{t}$ by $\mathrm{us}^{6}$ and is now called $\mathrm{Tme} / \mathrm{Te}$ by other workers ${ }^{81112}$ ). As normal post inspiratory muscle braking is lost in airways obstruction, Tme/TE decreases.

(2) $\mathrm{Krs}=$ decay constant of exponential fitted to tidal expiratory flow versus time curve during 
A

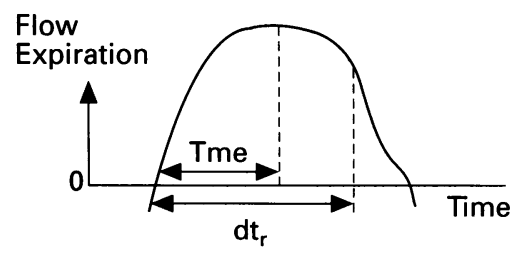

B

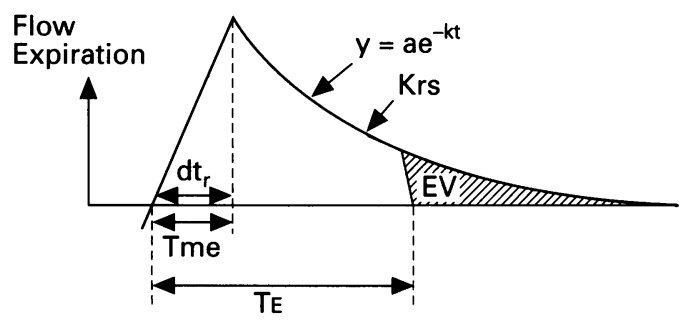

Figure 1 Schematic representation of tidal expiratory flow showing the appearance in $(A)$ a normal subject and (B) a patient with airways obstruction, and the derived indices Tme/TE, Krs, EV and dtr $/ T_{E}$. In some normal subjects $d t_{r} / T_{E}$ is greater than Tme/TE. When airways obstruction is induced $d t_{r} / T E$ approaches Tme/TE.

the second half of tidal expiration. In Otis' simple model of the respiratory system, ${ }^{8}$ consisting of a single compartment of constant elastance served by a pathway of constant resistance, the decay of flow or volume against time should be a single exponential. Applied to spontaneous breathing this model assumes no respiratory muscle activity or laryngeal braking over the range that the exponential is fitted. Then compliance $\times$ resistance $=1 / \mathrm{Krs}$ where $1 / \mathrm{Krs}=$ time constant of the respiratory system. In asthma, assuming compliance is unchanged, Krs decreases as resistance increases.

(3) $\mathrm{EV}=$ extrapolated volume - that is, area under the curve when the fitted exponential is extrapolated to zero flow. $\mathrm{EV}$ is the volume of the end expiratory tidal volume (FRC) above the relaxation equilibrium volume of the respiratory system. $^{7}$

In this study we have added a fourth index, $\mathrm{dt}_{\mathrm{r}} / \mathrm{TE}$ (fig 1), which is a revised version of the original Tme/TE (see Methods section for description).

The main aim of this study was to see whether, in the most difficult cases when within subject variability is maximum ${ }^{4}$ - that is, subjects with normal lung function who develop very mild airways obstruction - this analysis, using all the indices that we have described, could detect change. We studied adult patients in whom airways obstruction was induced by inhalation of histamine to determine whether (1) acute overinflation (acute change in FRC) could be detected and quantified by analysis of tidal expiratory flow pattern, and (2) the indices $\mathrm{Tme} / \mathrm{TE}, \mathrm{dt}_{\mathrm{r}} / \mathrm{TE}$, and $\mathrm{Krs}$ could detect an increase in airways obstruction and whether changes in these indices correlated with changes in other recognised indices of airways obstruction.

\section{Methods}

Twenty consecutive patients, 10 men, of mean age $45 \cdot 3$ (range 29-71) years, two current and six ex-smokers, undergoing histamine bron- chial challenge in our laboratory for clinical indications were studied. These patients were known to suffer from asthma or had presented with episodic cough and/or shortness of breath for which a diagnosis was being sought. Forced expired volume in one second $\left(\mathrm{FEV}_{1}\right)$ was measured with a Vitalograph spirometer and specific inspiratory conductance (sGaw) and functional residual capacity (FRC) were measured and spirometry repeated in a Jaeger Masterlab constant volume plethysmograph before the histamine challenge test. Histamine was inhaled in increasing concentrations via a Wright's nebuliser according to the protocol of Cockcroft. ${ }^{15} \mathrm{~A}$ run of at least 10 breaths of tidal breathing (flow versus time) was recorded at the completion of the above tests using a Fleisch no. 3 pneumotachograph and Gould Brush recorder 260 in 18 patients and RASP computer program ${ }^{16}$ in the last two patients. The analogue flow signal was taken into an Elonex PC-433 via Analogue Devices 12 bit A/D interface card, sampling rate $80 /$ second. The Fleisch pneumotachograph, tubing, preamplifier and recorder system were tested over the range of $0-21 / \mathrm{s}$ and found to have a linear response over this range. The Gould recorder had a frequency response flat up to $60 \mathrm{~Hz}$. Flow was calibrated with a flow signal of $11 / \mathrm{s}$ via a rotameter and the flow signal was integrated to give volume. Tidal flow over five consecutive representative breaths was analysed to give mean Tme/TE. An exponential was fitted to the flow versus time decay during the period between $50 \%$ and $90 \%$ tidal volume expired beginning where, by eye, the rapid decay of flow was deemed to begin (starting point $50-70 \%$ of tidal volume expired) (figs 1 and 3). Mean Krs and EV for the same five breaths were calculated. When the RASP computer program was used (in the last two patients) a straight line was fitted to the flowvolume curve from the onset of rapid decay of flow to determine $\mathrm{Krs}$, the slope of this line (fig 2). A revised index $\mathrm{dt}_{\mathrm{r}} / \mathrm{TE}$ was calculated as the time from the beginning of expiration until the exponential decay began (rather than the peak) divided by expiratory time (fig 1). Within observer variation of $\mathrm{dt}_{\mathrm{r}} / \mathrm{TE}$ expressed as coefficient of variation was $11 \%$ baseline and $8 \%$ after histamine. Between observer coefficient of variation was $7 \%$ baseline and $7 \%$ after histamine. Because in some normal subjects there was a plateau of flow after the peak was reached before the exponential decay began, this index was larger than Tme/TE (paired $t$ test, $\mathrm{t}=3.62, \mathrm{p}=0.0005$ baseline, and $\mathrm{t}=$ $1 \cdot 65, p=0.05$ after histamine) (fig 1). Indices of respiratory pattern, frequency $f$, tidal volume $\mathrm{VT}$, mean inspiratory flow rate $\mathrm{VT} / \mathrm{Ti}$, and inspiratory duty cycle Ti/Tтот, were calculated from the same five breaths. These tests were repeated after the final inhalation of histamine. The histamine challenge test was concluded in 12 patients when $\mathrm{FEV}_{1}$ had decreased by $20 \%$ of the post saline value, and in the remaining eight patients after inhalation of histamine at a concentration of 16 or $32 \mathrm{mg} / \mathrm{ml}$ (range of final histamine concentration $0 \cdot 125-32 \mathrm{mg}$ / $\mathrm{ml})$. 

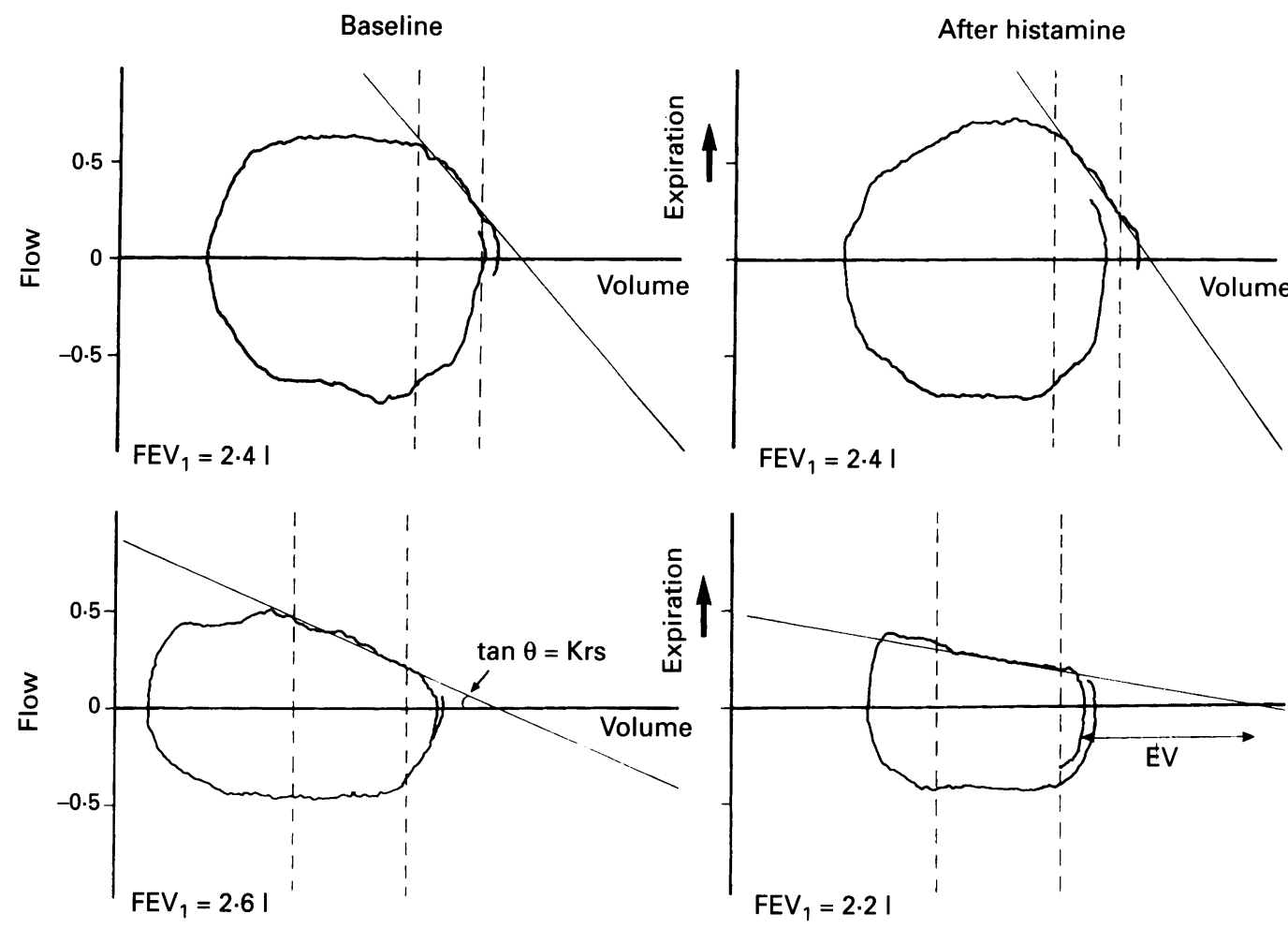

Figure 2 Tidal flow-volume tracings (RASP computer program) in two patients showing linear decay of flow against volume before and after histamine. The straight line was fitted between the dotted lines. The upper two graphs show no change in slope (Krs) or in EV in a normal subject whose FEV, did not change after histamine. The lower two graphs show a decrease in slope and increase in $E V$ in a mild asthmatic whose $F E V_{1}$ decreased.

\section{DATA ANALYSIS}

Regression analysis was carried out to describe the relationships between the various indices in the cross sectional group after histamine inhalation, and between the percentage change of the various indices resulting from the inhalation of histamine. The paired $t$ test was used to test whether significant change had occurred in the individual indices with the inhalation of histamine. The square of Pearson's correlation coefficient $(r)$ for the linear regression between log flow measured at $0 \cdot 2$ second intervals and time was taken as a measure of goodness of fit of the exponential and for the linear regression between flow and volume in the two subjects in whom the RASP computer program was used to analyse the tracings. On each subject, for each index, standard deviation (SD) was measured for the five breaths analysed before and after the inhalation of histamine. The paired $t$ test was used to test if there was any change in within subject variability as indicated by SD of any of the indices after histamine. A fall of $20 \%$ in $\mathrm{FEV}_{1}$ was taken as a positive challenge response to histamine. Sensitivity of a new method of detecting a positive histamine challenge was defined as the percentage of true positives found to be positive by the new technique and specificity as the percentage of true negatives found to be negative. A $35 \%$ fall in $\mathrm{Krs}$ was taken as the cut off between a positive and negative histamine challenge, as ROC curve analysis showed this to be the cut off that correctly assessed most subjects (17 of 20) and maximised the sum of sensitivity and specificity.

\section{Results}

Results of lung function measurements made before any inhalations and after the final inhalation of histamine are shown in table 1. All subjects had $\mathrm{FEV}_{1}$ greater than $70 \%$ predicted at the beginning of the study and the maximum fall in $\mathrm{FEV}_{1}$ in any subject was $40 \%$ of baseline value after the final inhalation of histamine. There was a consistent smoothing of the flow

Table 1 Mean (SD) lung function data in 20 patients before and after inhalation of histamine

\begin{tabular}{|c|c|c|c|c|c|c|c|c|c|}
\hline & \multicolumn{2}{|l|}{$F E V_{1}$} & \multicolumn{2}{|l|}{$F R C$} & $s G a w$ & $T m e / T E$ & $d t_{r} / T E$ & $K r s$ & $E V$ \\
\hline & litres & $\%$ pred & litres & $\%$ pred & \multicolumn{2}{|c|}{$\left(k P a^{-1} s^{-1}\right)(\%)$} & $(\%)$ & $\left(s^{-1}\right)$ & $(m l)$ \\
\hline $\begin{array}{l}\text { Baseline } \\
\text { After histamine } \\
\text { p }\end{array}$ & $\begin{array}{l}3.4(1.0) \\
2 \cdot 7(0.9) \\
<0.001\end{array}$ & $\begin{array}{r}102(16) \\
80(19)\end{array}$ & $\begin{array}{l}3.4(0.8) \\
3.9(0.9) \\
<0.01\end{array}$ & $\begin{array}{l}110(21) \\
126(26)\end{array}$ & $\begin{array}{l}2.6(0.9) \\
1 \cdot 1(1.4) \\
<0.001\end{array}$ & $\begin{array}{l}27(8) \\
26(12) \\
\text { NS }\end{array}$ & $\begin{array}{l}40(14) \\
33(15) \\
<0.005\end{array}$ & $\begin{array}{l}1.73(0.52) \\
1.08(0.62) \\
<0.001\end{array}$ & $\begin{array}{l}23(4) \\
146(14) \\
<0.01\end{array}$ \\
\hline
\end{tabular}

$\mathrm{FEV}_{1}=$ forced expiratory volume in one second; $\mathrm{FRC}=$ functional residual capacity; sGaw = specific inspiratory conductance; $\mathrm{Tme} / \mathrm{TE}, \mathrm{dt}_{r} / \mathrm{TE}, \mathrm{Krs}, \mathrm{EV}=$ indices derived from expiratory tidal fow (five breaths in each subject before and after histamine). p values indicate significance of difference between baseline values and those after histamine. 


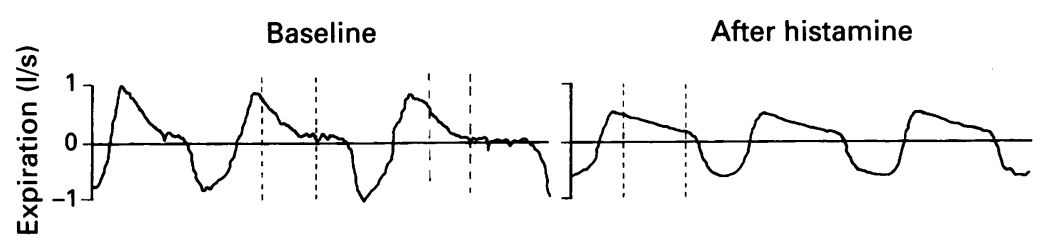

$(0.03)$ (after histamine). There was no difference between these two values (paired $t$ test $\mathrm{t}=0 \cdot 82, \mathrm{p}=\mathrm{NS}$ ).

Linear regression analysis in this group of 20 subjects after histamine showed that $\mathrm{Tme} / \mathrm{TE}$ correlated with $\mathrm{FEV}_{1}$ (slope $=0.31, r=0.49$, $\mathrm{p}<0.05)$ and with $\mathrm{sGaw}$ (slope $=7 \cdot 1, r=0 \cdot 82$,

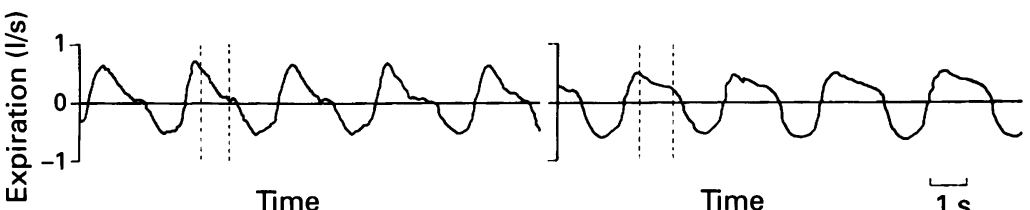

Figure 3 Tidal flow versus time in two subjects before and after challenge with

histamine. After histamine there are fewer small oscillations of flow and the expiratory

flow pattern has taken on a quadrilateral appearance with flow dropping sharply back to zero as inspiration is initiated. The exponential was fitted between the dotted lines. Actual recordings have been traced for clarity. $\mathrm{p}<0.001$ ), Krs with sGaw (slope $=0.28, r=$ $0.62, \mathrm{p}<0.01$ ) but not with $\mathrm{FEV}_{1}$, and the correlation of sGaw with $\mathrm{FEV}_{1}$ just missed statistical significance (slope $=0.004, r=0.42$, $\mathrm{p}<0 \cdot 1) . \mathrm{dt}_{\mathrm{r}} / \mathrm{TE}$ correlated with $\mathrm{FEV}_{1}$ (slope $=$ $0.43, r=0.56, \mathrm{p}<0.05)$ and with sGaw (slope $=$ $0.067, r=0.72, \mathrm{p}<0.001)$.

FEV $_{1} \quad(p<0.001)$, sGaw $(p<0.001)$, Krs $(p<0.001)$, FRC $(p<0.01), E V(p<0.01), d_{r} /$ TE $(p<0.005)$ were all significantly different after the inhalation of histamine (paired $t$ test); for Tme/TE no significant difference was shown versus time curve after bronchoconstriction was induced by histamine (fig 3). Mean (SD) $r^{2}$ values of the linear regression describing the $\log$ flow versus time relationship (and the linear flow-volume relationship in the two patients where RASP was used (fig 2)) during the period of rapid decay of flow in the second half of expiration were $0.96(0.03)$ (baseline) and 0.95

(figs 4 and 5). The volume increase in FRC after histamine was significantly different from the volume increase in $\mathrm{EV}(\mathrm{t}=2 \cdot 81, \mathrm{p}<0.01)$ (table 1) and linear regression of these two variables showed no significant relationship. After histamine the within subject SD of Krs decreased compared with baseline values from $0 \cdot 30 \mathrm{~s}^{-1}$ to $0 \cdot 21 \mathrm{~s}^{-1}(\mathrm{t}=2 \cdot 17, \mathrm{p}<0 \cdot 05)$, as did

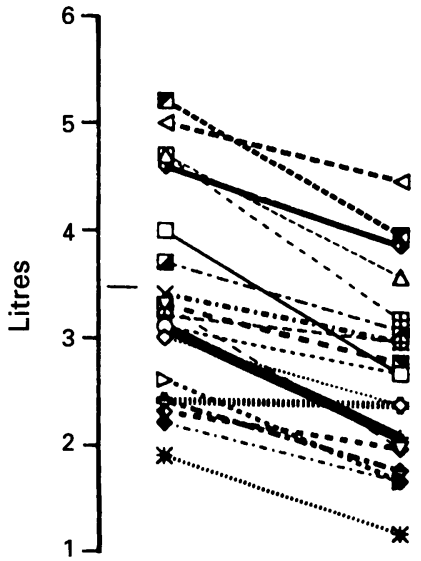

FEV $_{1}$

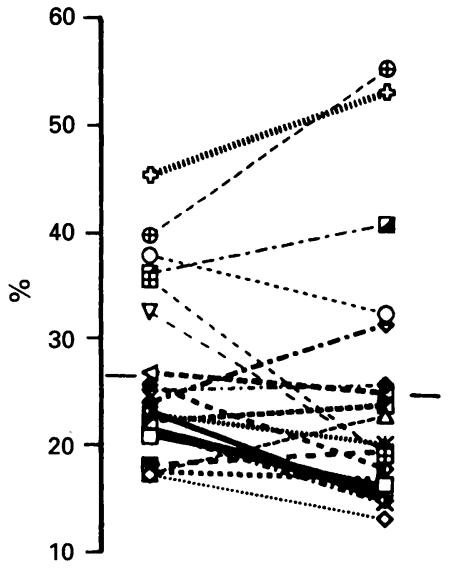

$\mathrm{Tme} / \mathrm{TE}$

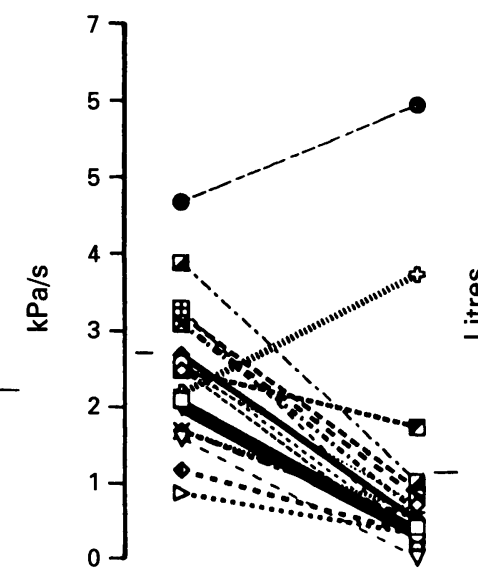

sGaw

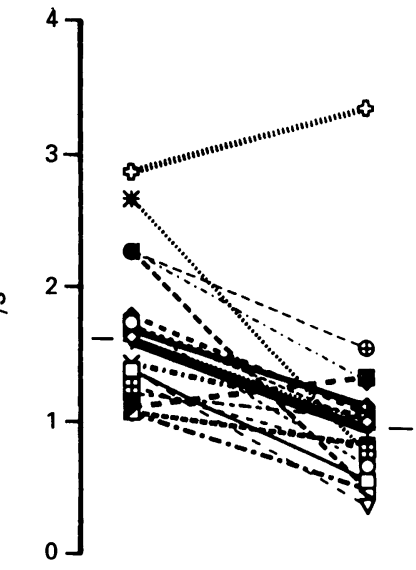

Krs

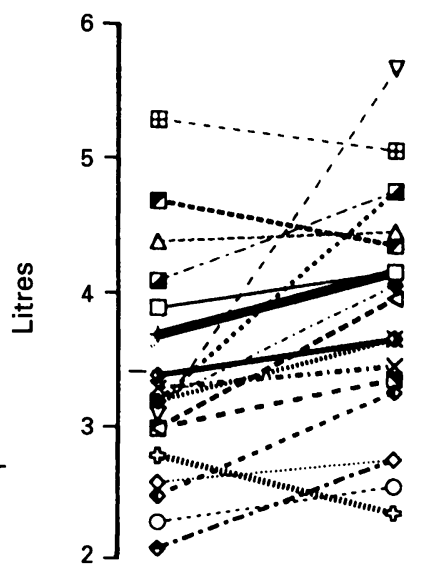

FRC

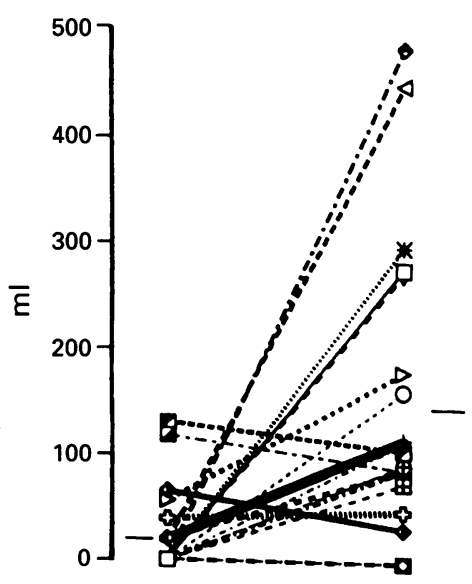

EV

Figure 4 Graphical representation of paired data before and after histamine inhalation for three recognised measures of airways obstruction ( $F E V_{1}$, sGaw and FRC), and for three indices derived from expiratory tidal flow pattern. All group means before and after histamine are statistically different except Tme/TE (see text). $-=$ group mean. 


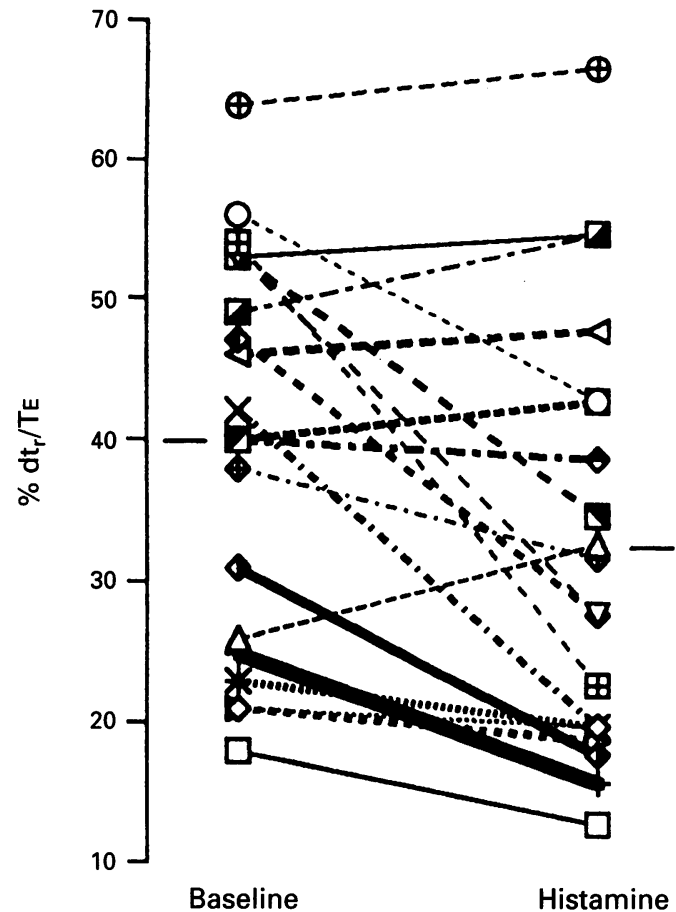

Figure 5 Changes in the index $d t_{r} / T E$ after histamine challenge, $p<0 \cdot 005$. - = group mean.

SD of $\mathrm{dt}_{\mathrm{r}} / \mathrm{TE}$ from $8 \cdot 9 \%$ to $5 \cdot 7 \% \quad(\mathrm{t}=2 \cdot 46$, $\mathrm{p}<0.03)$. There was no change in within subject variation of $\mathrm{SD}$ of the other indices, $\mathrm{Tme} / \mathrm{TE}$ and EV.

With linear regression analysis the percentage fall in Krs after the inhalation of histamine was shown to be significantly related to the percentage fall in $\mathrm{FEV}_{1}$ (fig 6, table 2). This was of an order similar to that of the relationship between the percentage fall in sGaw and the percentage fall in $\mathrm{FEV}_{1}$. The sensitivity of a $35 \%$ fall in $\mathrm{Krs}$ of predicting a $20 \%$ fall in $\mathrm{FEV}_{1}$ was $92 \%$, specificity $75 \%$. The sensitivity of a $35 \%$ (or $40 \%$ ) fall in sGaw (the usual index of a positive histamine challenge test) of predicting a $20 \%$ fall in $\mathrm{FEV}_{1}$ was $92 \%$, specificity $25 \%$. Table 2 shows regression relationships of the percentage change in the indices derived from expiratory flow against the percentage change in $\mathrm{FEV}_{1} \%$ predicted and in sGaw.

Frequency (f), tidal volume (VT), inspiratory duty cycle (Ti/TTOT) and mean inspiratory flow rate $(\mathrm{VT} / \mathrm{Ti})$ did not change after histamine, nor did the within subject SD of any of these indices.

Table 2 Summary of regression analyses of percentage change in expiratory flow indices against percentage change in $F E V_{1}$ (\% predicted) and sGaw after histamine inhalation

\begin{tabular}{|c|c|c|c|c|c|}
\hline$y$ axis & $x$ axis & Slope & Intercept & $r$ & $p$ \\
\hline $\begin{array}{l}\text { Krs } \\
\text { Krs }\end{array}$ & $\begin{array}{l}\mathrm{FEV}_{1} \\
\text { sGaw }\end{array}$ & $\begin{array}{l}1 \cdot 28 \\
0 \cdot 31\end{array}$ & $\begin{array}{l}10 \cdot 1 \\
18 \cdot 7\end{array}$ & $\begin{array}{l}0.52 \\
0.39\end{array}$ & $\begin{array}{l}<0.05 \\
\text { NS }\end{array}$ \\
\hline $\begin{array}{l}\text { Tme/TE } \\
\text { Tme/TE }\end{array}$ & $\begin{array}{l}\text { FEV }_{1} \\
\text { sGaw }\end{array}$ & $\begin{array}{l}0 \cdot 83 \\
0 \cdot 38\end{array}$ & $\begin{array}{l}-10 \cdot 5 \\
-16 \cdot 4\end{array}$ & $\begin{array}{l}0.38 \\
0.54\end{array}$ & $\begin{array}{l}\text { NS } \\
<0.05\end{array}$ \\
\hline $\begin{array}{l}\mathrm{dt}_{r} / \mathrm{TE} \\
\mathrm{dt}_{\mathbf{r}} / \mathrm{TE}\end{array}$ & $\begin{array}{l}\mathrm{FEV}_{1} \\
\text { sGaw }\end{array}$ & $\begin{array}{l}0.5 \\
0 \cdot 34\end{array}$ & $\begin{array}{r}6 \cdot 3 \\
-3.9\end{array}$ & $\begin{array}{l}0.22 \\
0.46\end{array}$ & $\begin{array}{l}\text { NS } \\
\text { NS } \\
(<0 \cdot 1)\end{array}$ \\
\hline sGaw & $\mathrm{FEV}_{1}$ & 1.67 & $26 \cdot 0$ & 0.54 & $<0.05$ \\
\hline
\end{tabular}

For definition of abbreviations see footnote to table 1 .
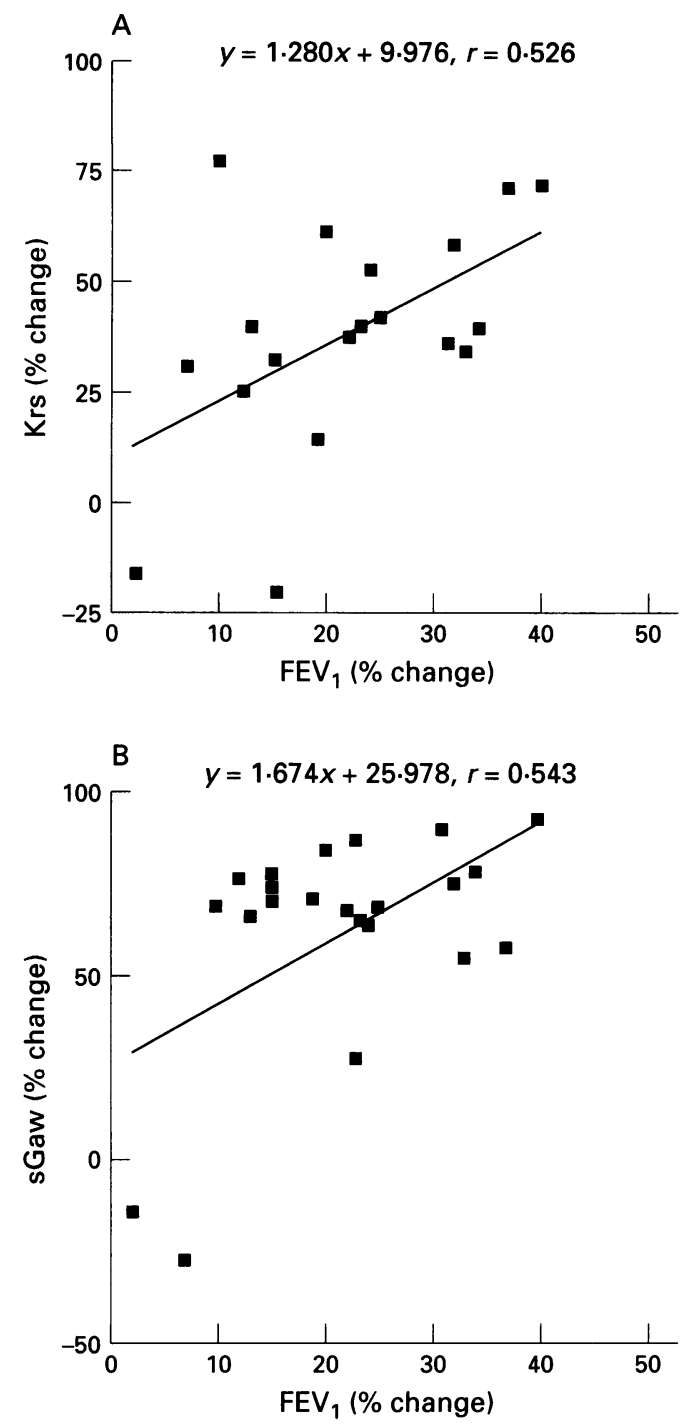

Figure 6 Graphs showing (A) \% change in Krs and (B) sGaw versus \% change in FEV $V_{1}$ after histamine challenge.

In 17 other normal subjects repeated measurements $(n=101)$ were made of these new indices from tidal breathing on the same and different days. Mean within subject standard deviations were $\mathrm{Krs} 0.58 \mathrm{~s}^{-1}$, Tme/TE $7 \%$, dt $/$ TE $7 \%$, EV 0.02 litres, coefficients of variation Krs $21 \%$, Tme/TE $21 \%$, and $\mathrm{dt}_{\mathrm{r}} / \mathrm{TE} 10 \%$. In 11 patients with airways obstruction $\left(\mathrm{FEV}_{1} 47\right.$ (21)\% predicted) mean within subject standard deviations (33 measurements) were $\mathrm{Krs}$ $0.06 \mathrm{~s}^{-1}$, Tme/Te $1.5 \%, \mathrm{dt}_{\mathrm{r}} / \mathrm{TE} 3.8 \%$, EV 0.05 litres, coefficients of variation $\mathrm{Krs} 7 \%$, Tme/ TE $6 \%, \mathrm{dt}_{\mathrm{r}} / \mathrm{TE} 10 \%$, and EV $16 \%$.

\section{Discussion}

This study shows that analysis of tidal breathing gives indices that can detect both increase in airways obstruction and increase in end tidal volume after histamine inhalation.

Histamine-induced bronchoconstriction was used as a model of asthma so that acute changes in FRC could be studied. The size of the significant change in EV which occurred after the inhalation of histamine did not correlate with the change in the plethysmographically 
measured FRC. Where the plethysmograph measured large changes in FRC, changes of similar magnitude were not detected by the extrapolated volume method. Plethysmography has been shown to overestimate lung volume in patients with airways obstruction, ${ }^{1718}$ and it may be that FRC measured in this way is overestimated after histamine when bronchoconstriction has been induced. ${ }^{18}$ In some of these subjects such big changes in FRC seem surprising in the face of such mild airways obstruction. The usual precautions of keeping the cheeks flat when the shutter came across and panting at low frequency were taken, but the compliant upper airways were not otherwise controlled. The other alternative is that the large plethysmographically measured volume changes are true and that the extrapolated volume method underestimates the volume change. One explanation of this second possibility is that the expiratory tidal flow curve, with its fitted exponential and extrapolated volume, refers only to that part of the lung subtended by open airways during tidal breathing. In this case the change in $\mathrm{EV}$ is the increase in lung volume of this section of the lung and does not include the increase in lung volume due to an increase in trapped gas in parts of the lung beyond the closed airways. This latter increase in lung volume will be included in the body plethysmographic measurement of lung volume. If this hypothesis is correct, the change in EV should correlate better with the change in lung volume when the latter is measured by helium dilution.

Assumptions made using the extrapolated volume method include (1) that there is no respiratory muscle activity or laryngeal braking during the time over which the exponential is fitted, ${ }^{79-22}$ (2) that a single exponential describes the decay of flow towards the end of resting tidal expiration, ${ }^{823-25}$ and (3) that the relaxation equilibrium volume of the respiratory system does not change with the induction of bronchoconstriction. There are theoretical objections to each of these assumptions ${ }^{222-29}$ which, because of limitations of space, cannot be discussed in this paper. However, our findings that (1) the fit of a single exponential to the flow versus time curve towards the end of tidal expiration is good both before and after histamine, and (2) that the baseline time constant $(1 / \mathrm{Krs})$ for the group ( 0.58 seconds) calculated from this exponential approaches the previously determined time constant of free collapse from TLC in consciously breathing and paralysed normal subjects, ${ }^{19232528}$ lead us to conclude that this analysis should give an approximate estimate of acute dynamic hyperinflation not including trapped gas. Our data show that a change in the tidal expiratory flow pattern sensitively detects the occurrence of acute hyperinflation, but underestimates the plethysmographically measured change in volume.

We have confirmed previous cross sectional findings $s^{6-810}$ in that the indices of airways obstruction, Krs and Tme/TE, derived from the tidal flow pattern, correlated with other recognised indices of airways obstruction in these subjects after histamine inhalation, as did the new index, $\mathrm{dt}_{\mathrm{r}} / \mathrm{TE}$.

We did not find change in Tme/TE as useful an index of airways obstruction induced by histamine in adults as the related volume index has been found by Cutrera et al in children. ${ }^{11}$ This difference may be attributable to the smaller number of subjects in our study and to the wider range of bronchoconstriction in their study, 15 of their 41 subjects having a fall in $\mathrm{FEV}_{1}$ of $40-70 \%$ of baseline after histamine. In our study no patient had a fall in $\mathrm{FEV}_{1}$ greater than $40 \%$ of the baseline value.

The regression coefficients between percentage change of the new indices and percentage change in $\mathrm{FEV}_{1}$ and sGaw after histamine were all positive (table 2), but the relationship was only significant between $\mathrm{Krs}$ and $\mathrm{FEV}_{1}$ and between Tme/TE and sGaw. Although the correlation between change in $\mathrm{Krs}$ and change in $\mathrm{FEV}_{1}$ was weak, change in Krs detected histamine-induced bronchoconstriction, measured by change in $\mathrm{FEV}_{1}$, as well as did sGaw, being equally sensitive and more specific. Krs, which is the reciprocal of the time constant of the respiratory system, depends on compliance as well as on airways resistance. Other accepted measurements of airways obstruction - for example, peak expiratory flow and $\mathrm{FEV}_{1}$ - are also non-specific, being affected by muscle strength, chest wall and lung recoil, lung and airways compliance, as well as by the calibre of the airways. Despite this, these measurements are extremely useful in the practical assessment of airways obstruction. The lack of specificity of the indices of tidal expiration, Krs, Tme/TE, and $\mathrm{dt}_{\mathrm{r}} / \mathrm{TE}_{\mathrm{E}}$, does not therefore rule them out as potentially useful in the assessment of airways obstruction.

The model of asthma that we chose caused only mild bronchoconstriction rather than significant clinical asthma. The visual impression of less variability in the tidal expiratory flow pattern in airways obstruction than in normal subjects, that we in this study and others ${ }^{4}$ have commented on, is documented in this study as a decrease within subjects of SD of $\mathrm{Krs}$ and of $\mathrm{dt}_{\mathrm{r}} / \mathrm{TE}$ after histamine compared with baseline SDs. It is our belief that change from normality to very mild airways obstruction is a "worst case" scenario for this analysis because of the variability of these indices in normal subjects as described by Buohuys. ${ }^{4}$ We are encouraged by the modest success of this analysis in detecting these small changes after histamine, and a study is underway to test the usefulness of this analysis in acute severe asthma where the practical benefits of a test not requiring respiratory gymnastics will be more evident. In the computer analysis a straight line is fitted to the expiratory flow-volume decay rather than, as in the first part of this study, an exponential to the flow-time decay. This is an improvement to the method because immediate assessment by eye of the goodness of fit of the imposed line and thus of the validity of the derived results is possible.

There is no doubt that a reliable method of quantifying the degree of airways obstruction, requiring from the patient only a run of tidal 
breathing through a pneumotachometer, would be useful in situations where maximum forced manoeuvres are unreliable or inapplicable.

The authors are grateful to Allen \& Hanburys for their support of the Osler Chest Clinic Lung Function Laboratory. RG Madgwick is the Allen \& Hanburys Respiratory Technician. We also thank P McShane for his help with the statistical analysis.

1 Have J Th ten. Over adensnelherd, adengrootte en ademarbeid. Thesis, University of Utrecht, The Netherlands, 1905.

2 Englmann K. Arch Klin Med 1927;157:280.

3 Kaye R, Whittenberger JL, Silverman L. Respiratory airflow patterns in children. Am $\mathcal{f}$ Dis Child 1949;77:625-41.

4 Bouhuys A. The clinical use of pneumotachography. Acta Med Scand 1957;159:91-103.

5 Phelan PD, Williams HE, Freeman M. The disturbance of ventilation in acute viral bronchiolitis. Aust Paediatr $\mathcal{f}$ 1968;4:96-104.

6 Morris MJ, Lane DJ. Tidal expiratory flow patterns in airflow obstruction. Thorax 1981;36:135-42.

7 Morris MJ, Madgwick RG, Frew AJ, Lane DJ. Breathing muscle activity during expiration in patients with chronic airflow obstruction. Eur Respir f 1990;3:901-9.

8 Otis AB, Fenn WO, Rahn H. Mechanics of breathing in man. F Appl Physiol 1950;2:592-607.

9 Martinez FD, Morgan WJ, Wright AL, Holberg CJ, Taussig LM. Diminished lung function as a predisposing factor LM. Diminished lung function as a predisposing factor for wheezing resp

10 Morgan WJ, Tepper RS, Wilcox E, Taussig LM, CHMA Pediatricians. Shape and moment analysis of tidal expiration in normal and bronchopulmonary dysplasia infants. Am Rev Respir Dis 1984;129(Suppl 2):A215.

11 Cutrera R, Filtchev SI, Merolla R, Willim G, Haluska J, Ronchetti R. Analysis of expiratory pattern for monitoring bronchial obstruction in school-age children. Pediatr Pulmonol 1991;10:6-10.

12 Carlsen $\mathrm{KH}$, Lodrup KC. Tidal flow volume loops in the assessment of reversibility to salbutamol in pre-school children with and without asthma. Eur Respir $\mathcal{F}_{1992}$; 5(Suppl 15):276s

13 Stocks J, Jackson E, Gappa M, Mukhtar Z, Costeloe K, Dezateux C. Analysis of tidal expiration - how stable is Tme/TE? Eur Respir f 1992;5(Suppl 15):38s.

14 Stich SM, Ellis E, LeSouef PN, Sly PD. Validation of respiratory inductance plethysmography ("Respitrace") for the measurement of tidal breathing parameters in newborns. Pediatr Pulmonol 1992;14:187-92.

15 Cockcroft DW, Killian DN, Mellon JJA, Hargreave FE. Bronchial reactivity to inhaled histamine: a method and clinical survey. Clin Allergy 1977;7:235-43.

16 RASP Respiratory Analysis Program users' guide. Newbury, UK: Physiologic Ltd.

17 Shore S, Milic-Emili J, Martin JG. Assessment of body plethysmographic technique for the measurement of thorpic vas volume in asthmatics. Am Rev Respir Dis 1982; 126:515-20.

18 Stanescu DC, Rodenstein D, Cauberghs M, Van de Woestijne KP. Failure of body plethysmography in bronchial asthma. $\mathcal{F}$ Appl Physiol: Respirat Environ Exerc Physiol 1982; 52:939-48.

19 Shee CD, Ploy-Sang-sang Y, Milic-Emili J. Decay of inspiratory muscle pressure during expiration in conscious humans. F Appl Physiol 1985;58:1859-65.

20 Agostoni E. Dynamics. In: Campbell EGM, Agostoni E, Newsome Davis J, eds. The respiratory muscles mechanics and neural control. London: Lloyd-Luke (Medical Books) and neural contro

21 Mortola JPO, Milic-Emili J, Noworaj A, Smith B, Fox G, Weeks S. Muscle pressure and flow during expiration in infants. Am Rev Respir Dis 1984;129:49-53.

22 Citterio G, Agostoni E, del Santo A, Marazzini L. Decay of inspiratory muscle activity in chronic airflow obstruction. 7 Appl Physiol: Respirat Environ Exerc Physiol 1981;51: 1388-97.

23 Pierce JA. Studies of free collapse in the intact human lung. 7 Lab Clin Med 1959;54:96-106.

24 Brody AF. Mechanical compliance and resistance of the lung thorax calculated from the flow recorded during passive expiration. Am f Physiol 1954;178:189-96.

25 Mclloy MB, Tierney DF, Nadel JA. A new method for measurement of compliance and resistance of lungs and thorax. F Appl Physiol 1963;18:424-7.

26 Muller N, Bryan AC, Zamel N. Tonic inspiratory muscle activity as a cause of hyperinflation in histamine-induced asthma. 7 Appl Physiol: Respirat Environ Exerc Physiol 1980; 49:869-74.

27 Martin J, Powell E, Shore S, Emrich J, Engel LA. The role of respiratory muscles in the hyperinflation of bronchial of respiratory muscles in the hyperinflation

28 Chelucci GL, Brunet F, Dall' Ava-Santucci J, Dhainaut JF, Paccaly D, Armaganidio A, et al. A single compartment model cannot describe passive expiration in intubated paralysed humans. Eur Respir f 1991;4:458-64.

29 Freedman S, Tattersfield AE, Pride NB. Changes in lung mechanics during asthma induced by exercise. 7 Appl Physiol 1975;38:974-82. 